\title{
MISCEL·LÀNIA
}

\section{EBUSUS Y LOS MONUMENTA ROMANOS DE LAS MURALLAS RENACENTISTAS DE IBIZA}

\author{
EBUSUS AND THE ROMAN MONUMENTS \\ OF THE RENAISSANCE WALLS OF IBIZA
}

Joan Ramon Torres

Departament de Patrimoni Històric, Consell d'Eivissa

\begin{abstract}
Resumen: En los años 90 del siglo XVI la construcción de las murallas renacentistas de Ibiza llegaba a su fin. En su entrada principal, la Puerta del Mar, fueron colocados un total de cinco monumentos romanos, largamente atribuidos a un hallazgo fortuito, en el curso de las obras. Gracias al buen gusto de sus ingenieros, habrían pasado a adornar el acceso monumental. Su vinculación con Ebusus siempre se ha dado por supuesta, pero un análisis exhaustivo de la bibliografía y los documentos históricos demuestra que tal creencia no surgió antes del siglo XVIII y suplió con fantasía lo que simplemente se ignoraba.
\end{abstract}

Palabras clave: estatuas romanas, Ebusus, Puerta del Mar, murallas renacentistas de Ibiza.

\begin{abstract}
In the 90s of the 16th century the construction of the Renaissance walls of Ibiza came to an end. At its main entrance, the Puerta del Mar, a total of five Roman monuments were placed, long attributed to a fortuitous find in the course of the works. Thanks to the good taste of their engineers, they would have gone on to decorate the monumental access. His association with Ebusus has always been taken for granted, but an exhaustive analysis of the bibliography and historical documents shows that such a belief did not emerge before the 18th century, supplying with fantasy what was simply ignored.
\end{abstract}

Keywords: Roman statues, Ebusus, Puerta del Mar, Renaissance walls of Ibiza. 


\section{Presentación $^{1}$}

Puede sorprender el título del presente artículo, puesto que hasta hace poco nadie había dudado de que las bien conocidas estatuas y las dos inscripciones romanas que, antes de ser sustituidas por réplicas en junio de 1980, formaban parte del acceso monumental a las murallas de Ibiza (figs. 1 y 2), habían pertenecido mucho antes, en los primeros siglos del Imperio, a Ebusus.

Con el transcurrir de los siglos, habían pasado a constituir un simple decorado, cuya explicación, en la mentalidad de eruditos locales y foráneos, no iba más allá de una feliz idea, de trasfondo ornamental, un gesto de buen gusto por parte de sus constructores.

Para quien suscribe, nacido a pocos metros de distancia de la puerta monumental, ${ }^{2}$ el frente norte del conjunto defensivo, con su impactante sistema de acceso, que incluía tales elementos, entonces ya revestidos de una dura pátina color dorado oscuro, fue siempre una imagen, aunque del todo familiar, no exenta de intriga.

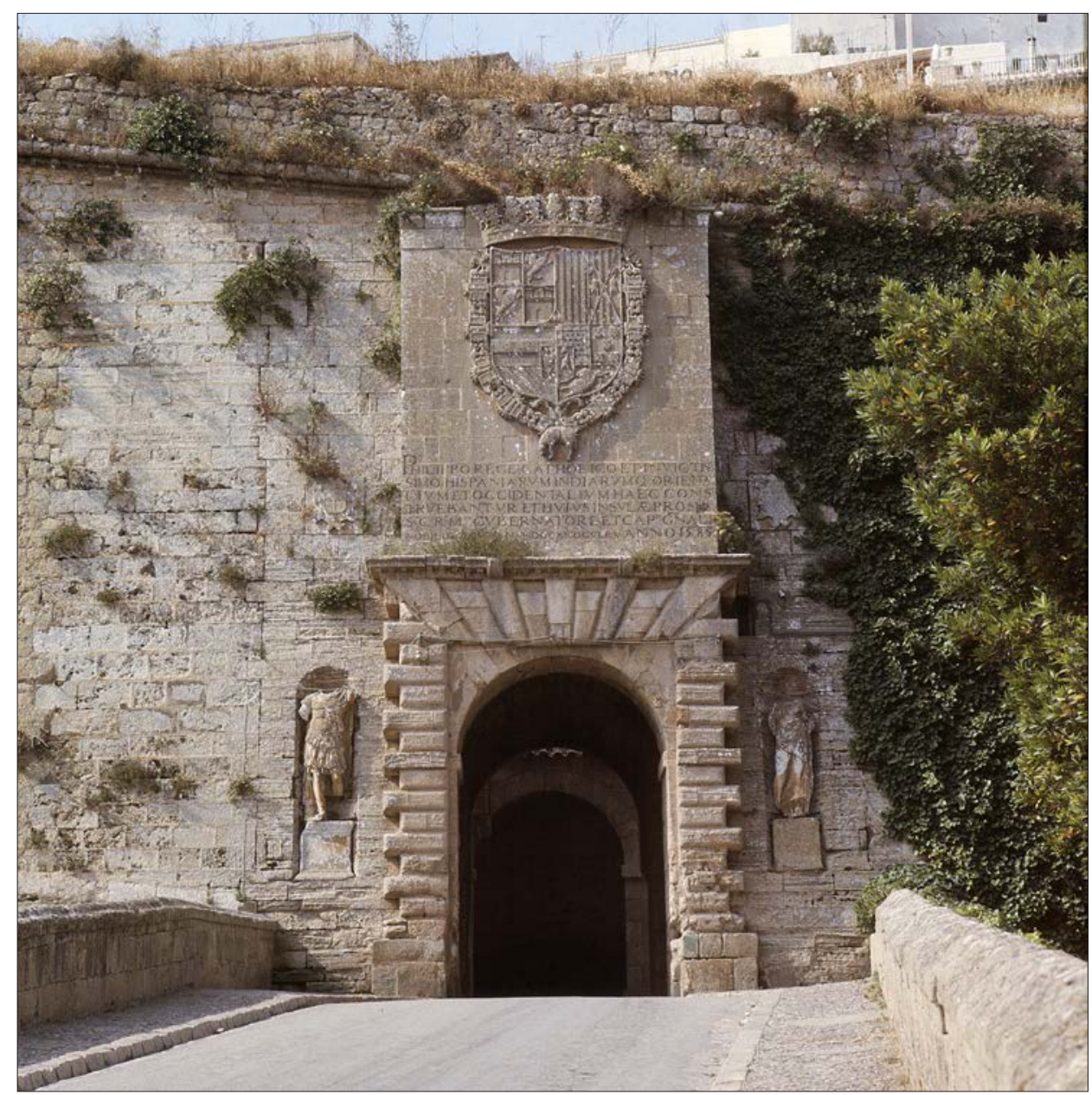

Figura 1. El Portal de ses Taules, con las lápidas y las estatuas auténticas

(Fuente: Manuel Arnaiz, 1970. Arxiu d'Imatge i So del Consell d'Eivissa).

\footnotetext{
1 Trabajo realizado en el marco del Grupo de Investigación CIVITAS de la Universitat de les Illes Balears.
}

2 Denominada «Es Rastrillo» en el lenguaje popular de aquel entonces; Portal de ses Taules, Puerta del Mar o de La Marina, en documentos históricos. 


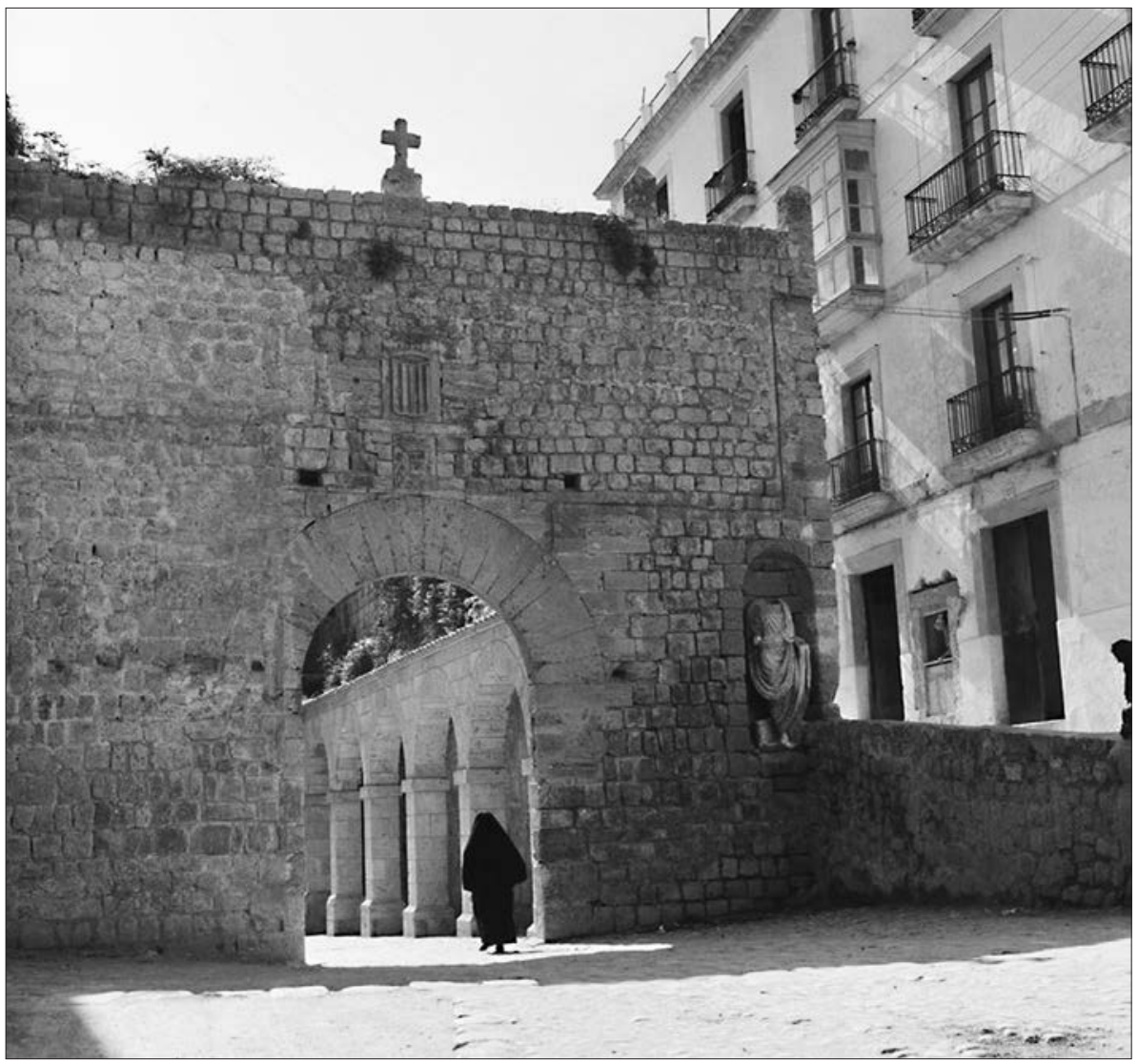

Figura 2. Entrada al cuerpo de guardia por el interior de la ciudad, verano de 1962. La estatua del togado es aún la auténtica, nótese que la casa adosada, mencionada por Piferrer y Quadrado, ya ha sido demolida (Fuente: J. M. Pando Barrero, IPCE, Fototeca del Patrimonio Histórico).

Mucho después, tras años de ejercer la profesión, se volvió complicado, no solo comprender, sino especialmente asumir, al menos sin una cierta frustración, el hecho de que multitud de intervenciones arqueológicas preventivas en la misma ciudad y en sus alrededores, llevadas a cabo a partir de mediados de los años $80,{ }^{3}$ no hubieran conse-

3 Joan Ramon Torres, «La ciutat romana d'Ebusus», Margarita Orfila Pons - Miguel Á. Cau Ontiveros (coords.), Ciutats romanes del llevant peninsular $i$ les Illes Balears. Barcelona: Els Juliols. Biblioteca Universitària, Enciclopèdia Catalana, 2004, p. 291-300; Ana Mezquida Orti, «Excavació arqueològica a la plaça de Sant Telm (Eivissa)», Quaderns d'Arqueologia Ebusitana 3 (2013), p. 27-31; Élise Marlière - Ángeles Martín Parrilla - Josep Torres Costa, «Rvbrvm, piperatvm et servilianvm. Algunos vinos y preparados vinarios consumidos en Ebvsvs», Monografías Ex Officina Hispana III (2016), p. 407-422. Otras muchas intervenciones arqueológicas permanecen aún inéditas. guido dar ni tan solo con fragmentos de estatuas romanas de semejante porte; se iba configurando una sospecha: que algo anómalo se escondía detrás de ello.

Como se analizará después, la construcción de la magna obra defensiva y el hallazgo de los monumenta romanos fueron, y lo siguen siendo, ${ }^{4}$ largamente vistos como un fenómeno de causa-efecto; cabrá que demostrar, por tanto — ya que no es

4 P. ej., Benjamín Costa Ribas - Jorge H. Fernández Gómez, Ibiza y Formentera, de la Prehistoria a la Época Islámica. Guía para la visita del Museo Arqueológico. Ibiza: Govern de les Illes Balears, 1995, p. 70: «Debieron ser halladas durante la construcción de las murallas renacentistas de la ciudad $[\ldots]$ las tres piezas fueron utilizadas como ornamento de la entrada principal $[\ldots]$ ». 
cuestión intrascendente-, que ello fue solo a partir de un momento tardío.

Modernamente, este conjunto de piezas romanas (fig. 3) ha sido estudiado, por una parte, en el marco del lote ibicenco de estatuaria, ${ }^{5}$ por otra, las dos inscripciones lo han sido conjuntamente con el resto de la epigrafía latina ebusitana, cuya tradición, mucho más larga, se remonta al siglo $\mathrm{XV}{ }^{6}$
Mientras que el verdadero origen de las estatuas sería susceptible de plantear aspectos relativos a la monumentalización y a la simbología en la ciudad de Ebusus y a la existencia de espacios públicos, como el foro, en el caso de las inscripciones, además de esto, la problemática abarcaría, entre otros, aspectos sociopolíticos, al incorporar personajes con nombres propios, algunos de los cuales, como después se dirá, son conocidos en paralelo por fuentes clásicas.

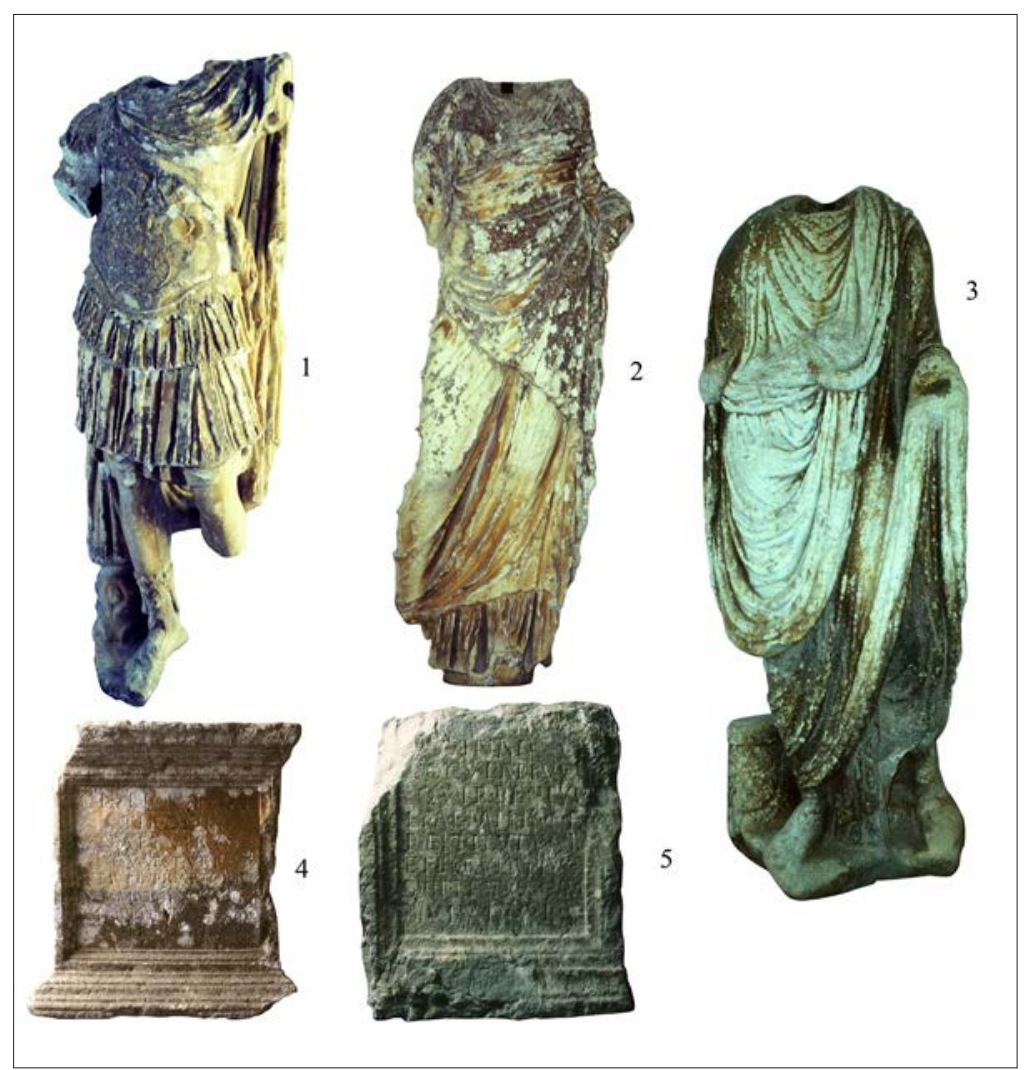

Figura 3. Los monumentos romanos originales del acceso monumental de las murallas renacentistas, ya en el Museo de Ibiza, antes de su limpieza (Fuente: archivo fotográfico MAEF).
5 Alberto Balil Illana, «Escultura romana de Ibiza», Trabajos del Museo Arqueológico de Ibiza 13 (1985), p. 5-16, aunque antes algunas de ellas habían sido objeto de otros trabajos: Alberto Balil Illana, «Esculturas de Andalucía y del Levante español», Zephyrus XII (1961), p. 203-207; Pilar Acuña Fernández, Esculturas militares romanas de España y Portugal. I.- Las esculturas thoracatas. Roma: Biblioteca de la Escuela Española de Historia y Arqueología en Roma, CSIC, 1975 , p. 51-55.

6 Jaime Juan Castelló, «Epigrafía romana de Ebusus», Trabajos del Museo Arqueológico de Ibiza 20 (1988), p. 25-30 y 32-39 EREB-1 y 3, recoge una bibliografía anterior muy amplia, en la que destacan trabajos como el de Cristóbal Veny Meliá, Corpus de las inscripciones baleáricas hasta la dominación árabe. Roma: Consejo Superior de Investigaciones Científicas, 1965, p. 1-282.
¿Pero, realmente estos monumentos existían en Ebusus o su único vínculo con Ibiza fue a raíz de la construcción de la fortificación renacentista? Es este, precisamente, el aspecto clave en el cual va a incidir el presente trabajo; no en vano, y como antes se ha dicho, su estudio específico e intrínseco, de carácter escultórico, en un caso, y epigráfico, en otro, con independencia de su lugar de procedencia, se ha realizado en múltiples ocasiones. 


\section{Ebusus}

En cuanto a la integración de Ebusus en la órbita romana, cabe recordar que las fuentes históricas no reflejan una conquista militar por parte de la República. Son bien conocidos dos episodios que tuvieron lugar en el marco de la Segunda Guerra Púnica: el primero fue el asedio a la ciudad de Gneo Escipión, en 217, que abandonó tras constatar que el esfuerzo era inútil ${ }^{7}$ y, el segundo, el refuerzo de la flota cartaginesa de Magón a su paso por la isla en 206 a. C. ${ }^{8}$ Estos episodios no hacen sino confirmar el carácter procartaginés de Ibiza, hecho lógico por otro lado, si se recuerda que se trataba precisamente de una apoikia cartaginesa. ${ }^{9}$

Más de dos siglos después, Plinio el Viejo ${ }^{10}$ se referiría a Ebusus como cinitas foederata, situación jurídica respecto a Roma, que entre la investigación moderna ha generado no pocas discusiones de índole cronológica. En unos casos, se ha pensado que dicho tratado, y previa deditio de la isla, se firmaría poco después de acabada la segunda contienda romano-cartaginesa (201 a. C.); en otros, y a nuestro entender con argumentos más convincentes, ${ }^{11}$ con la situación derivada de las guerras sertorianas (82-72 a. C.), algunos de cuyos escenarios se sitúan, precisamente, en Ibiza. ${ }^{12}$ Otra posibilidad, como ya se indicó en otra ocasión, ${ }^{13}$ menos explotada, y aún más tardía, podría

7 Tito Livio, Ab urbe condita, XXII, 20, 7.

8 Tito Livio, Ab urbe..., op. cit., XXVIII, 37, 3.

9 Diodoro de Sicilia, Biblioteca Histórica, V, 16.

${ }^{10}$ Plinio el Viejo, Naturalis Historia, III, 76-77.

${ }^{11}$ Enrique García Riaza, "Ciudades federadas de Baleares en la Antigüedad», Mayurqa 25 (1999), p. 167-176; Enrique García Riaza - María Luisa Sánchez León, Roma y la municipalización de las Baleares. Palma: Universitat de les Illes Balears, 2000, p. 102-117.

12 Plutarco, Sertorio, VII, 1.

${ }^{13}$ Joan Ramon Torres, «Economía y comercio de la Ibiza púnica en la época de las acuñaciones de moneda (siglos IV a. C. - I d. C.)», Alicia Arévalo González - Darío Bernal Casasola - Daniela Cottica (eds.), Ebusus y Pompeya, ciudades maritimas. Testimonios monetales de una relación. Cádiz: Universidad de Cádiz, 2013, p. 86. tener relación con el apoyo de la isla a la causa de Julio César, según se desprende de un parágrafo de Dión Casio (47 a. C.). ${ }^{14}$

En realidad, desde los puntos de vista tanto histórico como epigráfico, poco o nada se sabe de Ebusus hasta bien entrada la segunda mitad del siglo I de la era cristiana, ya en plena época altoimperial romana. El primer dato elocuente son las inscripciones que aluden tanto a la res publica Ebusitana como al municipium Flanium Ebusum, dos formas diferentes de indicar una misma realidad y no situaciones estatutarias distintas. Esta nueva situación jurídica, communis opinio, pues, se ha relacionado con la concesión universae Hispaniae, ${ }^{15}$ en el 73-74 d. C., del derecho latino (ius Latii), por parte del emperador Vespasiano. ${ }^{16}$

Otras inscripciones, que se fechan desde esta cronología en adelante, informan de personajes de la oligarquía ebusitana, principalmente los Oculatii y los Cornelii, de los cuales ahora solo cabe retener, de un lado, su pertenencia al ordo decurionum $\mathrm{y}$, de otro, sus acciones de evergetismo hacia la ciudad, como ha sido bien estudiado en otras ocasiones. ${ }^{17}$

Con la situación derivada del nuevo estatus de municipio romano se vincularían obras diversas de modernización y embellecimiento urbano; la construcción de un acueducto por los Cornelii sería un caso seguro y elocuente, y es en este marco donde los monumentos romanos de las murallas renacentistas, en teoría, podrían tener cabida y explicación. Pero, como se intentará demostrar después, con otros y mayores argumentos, sería solo en teoría, ya que se trata de piezas dispares, cuyas respectivas cronologías, al menos en algunos de los casos, son anteriores al hecho señalado.

${ }^{14}$ Dión Casio, Historia Romana, XXIX-XXX. Vid. Raimondo Zucca, Insulae Baliares. Le isole Baleari sotto il dominio romano. Roma: Carocci editore, 1998, p. 107.

${ }^{15}$ Plinio el Viejo, Naturalis..., op. cit., III, 30.

${ }^{16}$ María Luisa Sánchez León, «Ebusus, municipio flavio», Bolletí de la Societat Arqueologica Lul.liana. Revista d'estudis històrics 55 (1999), p. 55-64.

${ }^{17}$ Enrique García Riaza - María Luisa Sánchez León, Roma y la municipalización..., op. cit., p. 188-191 y 198202. 
Dicho esto, solo cabe recordar que la arqueología reciente demuestra que, sobre una base física heredada de la época tardopúnica, la ciudad altoimperial de Ebusus gozó de una notable extensión y prosperidad ${ }^{18} \mathrm{y}$, al menos desde este simple punto de vista, tampoco nada extraño tendría la incorporación a su ambiente urbano de estatuaria monumental romana.

\section{Análisis de la historiografía sobre los monu- mentos romanos de las murallas de Ibiza}

En primer lugar, es necesario referirse al manuscrito de Fra. Pere Vicent Nicolau, elaborado alrededor de 1620 , tenido por la primera historia (conocida) de Ibiza. A pesar de que siempre permaneció inédito, y de que actualmente se considera desaparecido, sirvió de base literal para un texto famoso, la llamada Resumpta. ${ }^{19}$

De este documento hay dos aspectos que conviene destacar: el primero es el interés de su autor en dejar constancia de una serie de hallazgos arqueológicos acaecidos durante las obras de fortificación en la parte de Santa Llúcia y en la del Mar, que sin duda provocaron importantes movimientos de terreno. En dicho original, y por supuesto también en la versión de su editor dieciochesco, se da cuenta de ello:

Cuando se abrieron las zanjas para echar los cimientos de la nueva fortaleza, en toda la parte que se llama Santa Lucía y en la del Mar se hallaron vestigios de antigua arquitectura, sepulcros y otros monumentos; aún en su tiempo dice que se hallaban muchas cisternas, y aljibes en los dichos lugares, cavados en peña viva de mucha antigüedad y de artificio propio de aquellos tiempos, lo que indica haber sido fabricados para uso de los pobladores de aquellos sitios, y arguye cuan mayor era la extensión de aquel poblado. Fueron también halladas [dice más] ruinas de

${ }^{18}$ Joan Ramon Torres, «La ciutat romana...», op. cit., p. 291-300.

19 Padre Cayetano de Mallorca, Resumpta historica, corographica y coronologica de las mismas islas, Reales ordinaciones de la isla y real fuerça de Iviza. Mallorca: Imp. de Miguel Cerdà, 1751, p. 20. un templo del Dios Mercurio edificado por los cartagineses, cuyas memorias ha confundido el tiempo. [...] Las ruinas de este templo, son las que más indican ser aquellos vestigios derruidos que lo acompañan, de pueblos cartagineses.

El segundo, que P. V. Nicolau, cuyo nacimiento se presume alrededor de 1584 , y que ya en 1596 fue nombrado subdiácono del convento de San Vicente Ferrer y San Jaime, ${ }^{20}$ situado en la parte superior del Puig de Santa Llúcia, por fuer$\mathrm{za}$, no solo fue testigo directo, sino que incluso lo fue desde el punto de vista cotidiano, de la fase final de la construcción de las murallas, incluida la Puerta del Mar, con la instalación de los monumentos romanos objeto del presente trabajo. Prueba de ello es que el hallazgo de cisternas y otros elementos antiguos en este sector, referido por Nicolau, ha sido completamente confirmado por la arqueología moderna. ${ }^{21}$

En efecto, los referidos trabajos de fortificación, que no tuvieron lugar en época del ingeniero G. B. Calvi, como se pensó hasta $1970,{ }^{22}$ sino de su sucesor, J. P. «el Fratin», afectaron no solo el Puig de Santa Llúcia (apéndice NE del Puig de Vila), sino también a la parte "del Mar», donde se halla precisamente el portal monumental del mismo nombre, que constituye el borde meridional del llano de La Marina.

Es por ello que llama poderosamente la atención el hecho de que no se mencionen en absoluto ni el descubrimiento ni la consiguiente instalación de estas piezas, detalle apercibido por J. Juan, ${ }^{23}$ con extrañeza, pero sin encontrarle explicación. Ciertamente, el hecho podría atribuirse a un descuido, pero también podría tener otras explicaciones: que en el momento de las obras, seguidas en directo por dicho escritor, las piezas

\footnotetext{
${ }^{20}$ Felip Cirer Costa, «Nicolau, Pere Vicent», Enciclopèdia d'Eivissa $i$ Formentera 9. Ibiza: Consell Insular d'Eivissa, 2006, p. 30.

${ }^{21}$ Joan Ramon Torres, «La ciutat romana...», op. cit., p. 271 y 276.

${ }^{22}$ Bartolomé Escandell Bonet, Aportación al estudio de las murallas renacentistas de Ibiza. Ibiza: Instituto de Estudios Ibicencos, 1970, p. 37-45.

${ }^{23}$ Jaime Juan Castelló, «Epigrafía romana...», op. cit., p. 27.
} 
no se vincularan al resto de las antigüedades ebusitanas, que sí describe en la Historia de Iviza. No parece, pues, una simple omisión, sino más bien un silencio elocuente.

En realidad, las estatuas y las dos inscripciones instaladas en el portal aparecen documentadas por primera vez en el año 1791 (fig. 4a), de la mano de Carlos González de Posada, de cuyo manuscrito original, conservado en la Real Academia de Historia, se ha podido disponer de reproducción facsímil. ${ }^{24}$ El canónigo magistral afirma:

Hay tres estatuas mayores que el tamaño del natural, que por estar decapitadas y mancas, y por el número, fueron creídas, hasta ahora los conquistadores de estas islas, el infante Don Pedro de Portugal, el Arzobispo de Tarragona Don Guillermo Mongriu y el caballero Don Nuño Sanz que en agosto de 1235 las quitaron a los moros. Estuvieron en otra parte hasta el reinado de Felipe II, en que se colocaron en sendos nichos dispuestos expresamente para recibirlas cuando se construyó la fortaleza actual. Pero ellas son romanas sin la menor duda. A los costados de la puerta principal que llaman de la Marina están las dos de mármol y de primorosa escultura [...]. Están sobre proporcionados pedestales de la misma materia y fecha que las estatuas, y con inscripciones latinas [...] C. Jul. Caes. C. F. $[\ldots]$ por donde infiero que la estatua compañera es de la mujer o madre de Julio Cesar, del cual se sabe que estuvo en Ibiza. Entrando esta puerta y pasado el cuerpo de guardia, que llaman principal, a un lado de la segunda puerta, que sale a la plaza, está la otra estatua, mucho mayor y casi colosal, vestida de toga de senador [...]. Me inclino a que aquel representa al emperador Marco Aurelio, que fue gran fautor de esta isla y querido de ella en sumo grado. ${ }^{25}[\ldots]$ sobre lo cual [se refiere aquí al hallazgo de tumbas en el Puig des Molins], si interesa a la Academia propongo hacer una disertación que haga verosímil

\footnotetext{
${ }^{24}$ Carlos González de Posada, «Adiciones a la Relación de Iviza del Ilmo. Sr. Don. Manuel de Abad primer Obispo de aquella diócesis» (1791), Biblioteca de la Real Academia de la Historia, códice E 136 , estante 27 , grada 5 a, folio 289 293. Este manuscrito fue transcrito, con otro título y algunas anotaciones de escaso interés, por Fidel Fita Colomé, «Ibiza, arqueológica e histórica en 1791, Dr. D. Carlos González de Posada», Boletín de la Real Academia de la Historia 51 (1907), p. 307-318.

${ }^{25}$ Ibid., p. 291, ap. 6.
}

esta noticia histórica hasta ahora no tocada por nadie cómo ni la de las estatuas.

Pasados dos tercios de siglo, ya en la segunda mitad del XIX, T. Aranaz 1859, ${ }^{26}$ maestro y periodista, ${ }^{27}$ dice textualmente (fig. $4 \mathrm{~b}$ ):

A los laterales del portal principal de la muralla, que conduce de la Marina a la ciudad, hay dos estatuas decapitadas. Los moradores han perdido la tradición de los personajes que las mismas representan, y algunos creen la ridiculez de que fueron dos criminales decapitados por sus delitos y expuestos a la execración pública. Por sus trajes de gran gala venimos a comprender fueron sujetos de alta categoría, mutilados por manos vandálicas, enterrados entre las ruinas de la devastación sarracena, encontrados después de la última conquista y mandados colocar por los reyes Católicos cómo dignidad y testimonio patente del lustre y glorias de la antigua Isla. [...] No queda la menor duda que tanto este busto cómo todos los demás fueron encontrados, cómo ya hemos manifestado, en las excavaciones practicadas para buscar piedra para la fábrica de las murallas, pues lo demuestra muy bien su mutilación y los golpes que recibiera al rodar el día de la devastación sarracena. ${ }^{28}$

Es, por tanto, el primero en afirmar que las estatuas debieron de ser encontradas al sacar piedra para la construcción de la muralla, aunque la historia que les adjudica sea, obviamente, una invención rocambolesca.

Pasados diez años, el archiduque Luis Salvador de Austria ${ }^{29}$ se limita a reproducir estas piezas en una xilografía, hace un comentario meramente descriptivo de estas y transcribe lo que ve (o lo que cree ver $)^{30}$ en las dos inscripciones. Pero, más allá de esto, no entra en consideraciones de ninguna clase.

26 Tomás Aranaz Barrera, Historia de la isla de Iviza. Ibiza: Imprenta científica y religiosa de la Juventud, 1859, p. 23.

${ }^{27}$ Francesca Tur Riera, «Aranaz i Barrera, Tomàs», Enciclopèdia d'Eivissa i Formentera 1. Ibiza: Consell d'Eivissa i Formentera, 1995, p. 199-200.

28 Tomás Aranaz Barrera, Historia de la..., op. cit., p. 23.

${ }^{29}$ Luis Salvador de Austria, Die Balearen in Wort und Bild geschildert. Die alten Pityusen. Leipzig: Brockhaus, 1869, p. 110-112.

${ }^{30}$ Jaime Juan Castelló, «Epigrafía romana...», op. cit, p. 25 y 33 . 


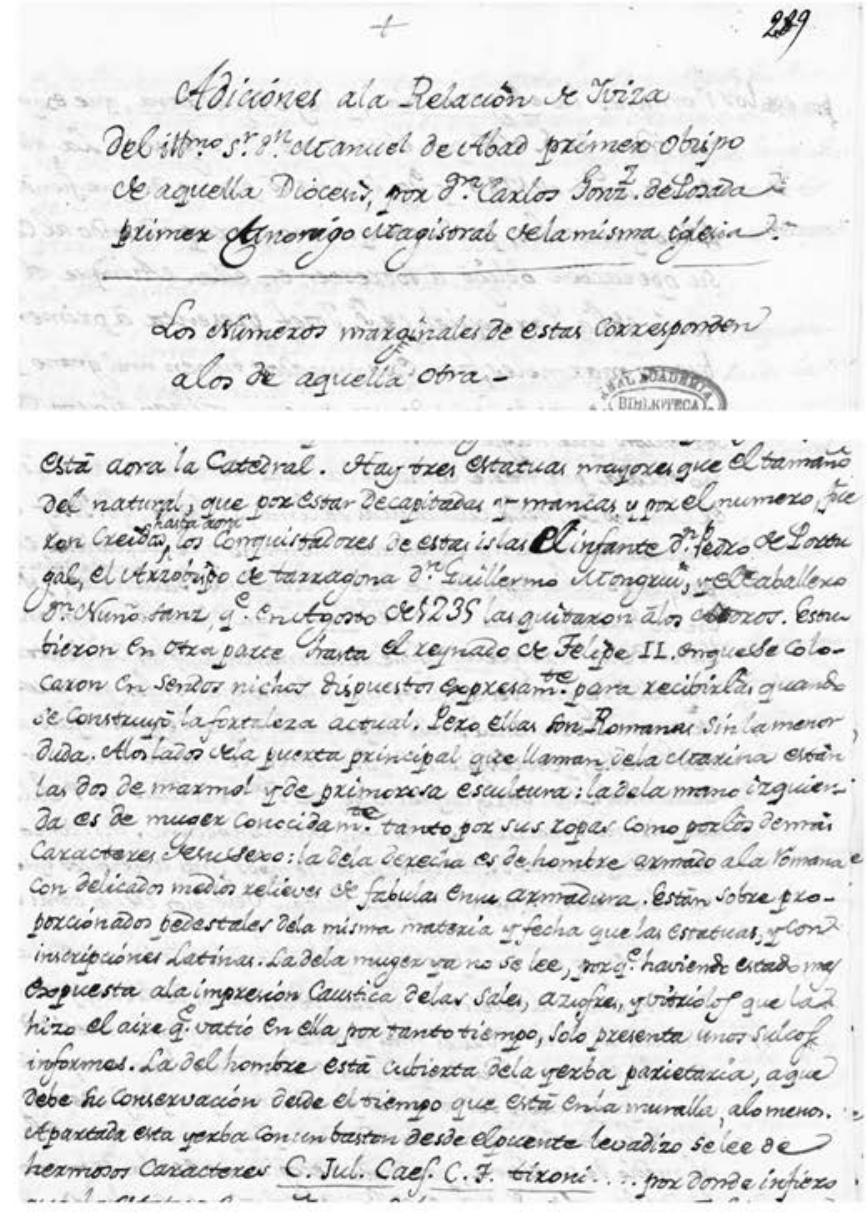

a

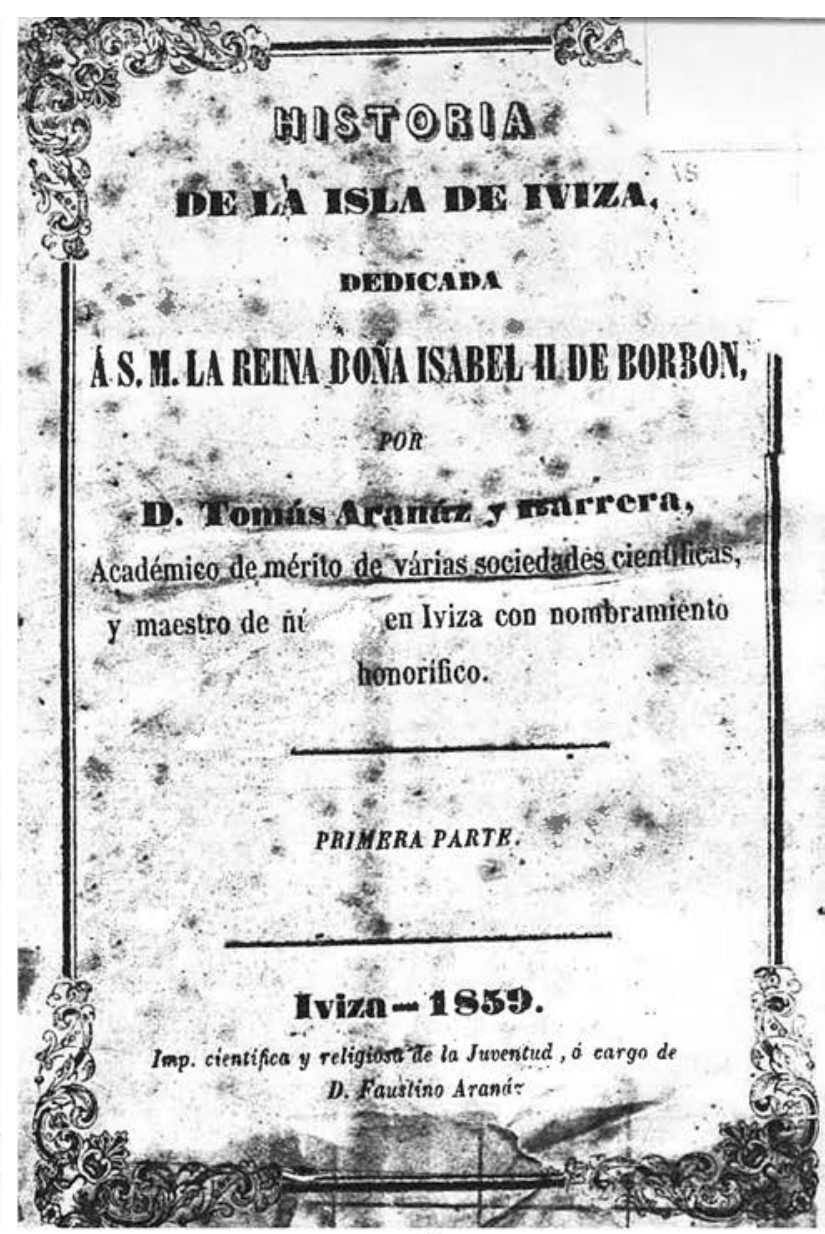

b

Figura 4. a) Fragmento del manuscrito original de Las adiciones de González de Posada (1791) que alude a los monumentos romanos de las murallas de Ibiza (Fuente: Biblioteca de la Real Academia de la Historia). b) Portada de la Historia de la isla de Iviza de Tomás Aranaz, publicada en 1859 (Fuente: Ayuntamiento de Ibiza, Archivo histórico).

Piferrer y Quadrado, dos décadas después, vinculan, igual que antes Aranaz, a la historia romana de Ibiza estos monumentos, aunque sin tanta imaginación:

Por una feliz inspiración colocáronse en simples hornacinas a los costados dos estatuas romanas, halladas probablemente al hacerse dichas obras con las inscripciones que les sirven de base [...] en el ángulo (el de la puerta que da a la plaza de las Herrerías, actualmente plaza de Vila) un nicho, por el estilo de los del portal, cobija la estatua de un togado [...] y acaso quedó oculta, si es que no pereció, la que ocuparía el nicho colateral, antes de que con facilidad deplorable se permitiera adosar al muro una casa moderna que desentona el severo cuadro. ${ }^{31}$

Ya a principios del siglo XX, los pioneros de la arqueología ebusitana, cuya línea de separación entre lo real y lo imaginario no era menos tenue

${ }^{31}$ Pau Piferrer - Josep M. Quadrado, España sus monumentos y artes. Su naturaleza e Historia. Islas Baleares. Barcelona: Ed. Daniel Cortezo y Cia, 1888, p. 591-592 y 608. Dicha casa fue demolida hace algunos años y pudo apreciarse que una cuarta hornacina no existió jamás. 
que la de sus predecesores del siglo anterior, al pretender otras precisiones sobre las supuestas circunstancias del hallazgo, llevaron el asunto incluso mucho más lejos, al menos en el caso de J. Román Calvet: ${ }^{32}$

A partir del antes citado punto (parece referirse al límite NE de la finca de can Francesquet), en dirección hacia el $\mathrm{N}$, fueron halladas tres grandes estatuas de piedra, faltas de cabeza, al extraer piedra para construir las actuales murallas, habiéndose colocado dos de ellas a ambos lados de la puerta principal de la ciudad fortificada y la otra en el ángulo de un muro interior que desde la ciudad da acceso al respectivo portal.

En realidad, al norte del límite de dicha finca (después llamada can Partit), no existían sino campos llanos, totalmente cultivados, un mal lugar para organizar una cantera, que, desde luego, no corroboran ni los textos conocidos sobre la construcción de las fortificaciones ni evidencia alguna sobre el terreno.

Y, poco después, A. Pérez-Cabrero, consideraba: «Al lado de las jambas del portal existen dos importantes estatuas romanas, encontradas en la época de la construcción de las murallas y, en la vía romana que va desde la Puerta Nueva a las Figueretas. Con muy buen acuerdo el ingeniero Calvi las hizo colocar en hornacinas construidas al efecto, así como también la del edil que está en la parte interior de la fortificación, plaza de $\mathrm{He}$ rrerías (sigue a continuación una breve descripción de estos monumentos que ahora no viene al caso)». Asimismo, añade: «[...] hace años, encontró el canónigo José Pujet [por Puget] la cabeza de la diosa [se refiere a la estatua femenina], que fue adquirida por el autor y entregada al Museo arqueológico, en donde está depositada hasta que se coloque en su correspondiente sitio». ${ }^{33}$

\footnotetext{
32 Juan Román y Calvet, Los nombres e importancia arqueológica de las islas Pythiusas. Barcelona: Tipografía L’Avenç, 1906, p. 36-37, lám. XLIII.

${ }^{33}$ Arturo Pérez-Cabrero Tur, Ibiza: Arte, Agricultura, Comercio, Costumbres, Historia, Industria, Topografia, Guia del Turista. Barcelona: Imprenta de Joaquin Horta, 1909, p. 59-60.
}

El mismo Pérez-Cabrero, en otra obra solo dos años posterior a la primera, indicaba:

Las grandes y bellas estatuas romanas que se hallaron en Ibiza en tiempos de Carlos V, cuando se excavaron los cimientos de las elegantes y costosas murallas $[\ldots]$ fue el ingeniero italiano Calvi, director de la elegante y grandiosa fortificación, quien hizo el importante descubrimiento, puesto que desde entonces están colocadas a ambos lados de las jambas de la puerta principal, dos de ellas en hornacinas construidas al efecto y hacen un precioso conjunto con la puerta y con su sin par escudo de armas que la decora con esplendidez original. La tercera estatua está colocada en otra hornacina, en la parte interior de la fortificación, en la plaza de Herrerías [... ] corresponde a un cipo sepulcral de la misma época, descubierto en las inmediaciones de esta ciudad, año $1834[\ldots] . .^{34}$

Obviamente, en este caso, Pérez-Cabrero se refiere al pedestal de Lucio Oculacio Recto y da por sentado que a este político municipal ebusitano - edil, duunviro y flamen, según reza la inscripción CIL II, 3662 / EREB-4- ${ }^{35}$ de la segunda mitad del siglo II d. C., si no más tarde, debía de corresponder forzosamente la estatua togada, que en realidad, y como se ha dicho, es de factura julio-claudia o flavia ${ }^{36}$ y que en época renacentista jamás recibió pedestal.

Evidentemente, a esta cita tampoco podían faltar C. Román: «al hacerse los trabajos de construcción de las citadas murallas, fueron encontradas las bellas estatuas romanas $[\ldots]{ }^{37} \mathrm{ni}$, por supuesto, A. Vives. Este último, además de repetir fielmente lo dicho por sus antecesores y coetáneos, hace una decisiva aclaración sobre la cabeza adquirida por Pérez-Cabrero:

\footnotetext{
${ }^{34}$ Arturo Pérez-Cabrero Tur, Ibiza arqueológica. Barcelona: Ed. Thomas. 1911, p. 42-45, fig. 38-41.

35 Jaime Juan Castelló, «Epigrafía romana...», op. cit., p. 39-43; Jaime Juan Castelló, «Els Oculacis d'Ebusus (a propòsit de nous testimonis)», Sylloge Epigraphica Barcinonensis, Anuario de Filología 17 (1994), p. 201-211.

${ }^{36}$ En opinión de Balil, autor que ha estudiado el conjunto ibicenco con más profundidad: Alberto Balil Illana, «Escultura romana...», op. cit., p. 8.

${ }^{37}$ Carlos Román Ferrer, Antigüedades ebusitanas. Barcelona: Tipografía La Académica, 1913, p. 28-29.
} 
Al construirse las murallas de la fortaleza de Ibiza en el siglo XVI, el arquitecto tuvo el buen acuerdo de decorar la puerta principal con estatuas romanas, encontradas, al parecer, en la parte baja de la necrópolis ebusitana; ellas son en número de tres y están sin cabeza; en el Museo de Ibiza se conserva una cabeza muy deteriorada, ${ }^{38}$ que se suponía pertenecer a una de dichas estatuas, pero en el transcurso de las excavaciones de la necrópolis, tuvimos la suerte de encontrar un arranque de busto de mármol, que resultó corresponder a la cabeza del Museo, adonde fue remitido, con lo que se ha comprobado que no perteneció a ninguna estatua. Consérvanse también algunas lápidas: dos de ellas sirven de pedestal a las estatuas antes citadas $[\ldots] .{ }^{39}$

En resumen, los arqueólogos y eruditos de inicios del siglo XX, que, no se olvide, escribieron pasados más de trescientos años desde la conclusión de la puerta monumental del recinto fortificado renacentista, se limitaron, uno tras otro, a emitir afirmaciones en la línea inaugurada medio siglo antes por T. Aranaz. Estas no dejaban de ser gratuitas a pesar de estar amparadas en una especie de lógica simplista, ante la ausencia de pruebas fehacientes, que jamás pudieron aportar.

Desde entonces y hasta ahora, han tenido lugar otros estudios que, de un modo u otro, han concernido estos monumentos romanos y que, al menos los principales, serán mencionados a lo largo del presente trabajo. Cabe ahora simplemente señalar que su enfoque se ha centrado en el análisis de los estilos escultóricos, las cronologías y los paralelos, en el caso de las estatuas y en las transcripciones y estudios de personajes, en el de las lápidas. Se ha considerado siempre, tras la estela de los viajeros y eruditos de siglos pasados, este conjunto monumental de hallazgo insular urbano, de probable vinculación con las obras del XVI, sin entrar nunca en el fondo de la cuestión, sin tan solo plantearse el problema.

\footnotetext{
${ }^{38}$ Juan Román y Calvet, Los nombres e importancia..., op. cit., lam LII, 1.

${ }^{39}$ Antonio Vives Escudero, Estudio de Arqueología cartaginesa. La necrópoli de Ibiza. Madrid: Imprenta de Blass y Cía., 1917, p. XLVI.
}

\section{Nuevos puntos de vista}

La situación antes descrita sufrió un cambio sustancial a raíz del encargo por parte del Ayuntamiento de Ibiza de un plan director de las murallas a un equipo de especialistas en fortificaciones del Renacimiento, cuyo proceso de redacción, iniciado en 2001, dio paso a interesantes intercambios de ideas en el círculo local. De ellas surgió una sospecha: que las inscripciones y las estatuas romanas que integraban podían no proceder realmente de la Ibiza romana. ${ }^{40}$

En esta línea, y en un trabajo algo posterior, ${ }^{41}$ se desarrolló algo más dicha hipótesis y se introdujeron definitivamente parámetros bien distintos en relación con la visión tradicional, que, desde una mentalidad rigurosa, no pueden ser ignorados, máxime cuando no solo afectan la mentalidad simbólica y compositiva del siglo XVI, sino también - y esto es lo que interesa ahora- a la propia historia de la ciudad romana de Ibiza.

En efecto, frente a la visión erudita, cuya base residía en un factor de azar - como, obviamente, lo era el hallazgo de tales piezas a raíz de la construcción de la fortificación o al simple hecho de su existencia previa en algún punto de la ciudad de Ibiza-, la nueva línea demostró sobradamente que el acceso monumental, a todos los niveles, fue diseñado bajo un esquema preconcebido y sobre todo muy estudiado, que incorporaba en su compositiva estas estatuas (fig. 5) y donde las casualidades se hallaban fuera de lugar.

Desde este punto de vista, el diseño y la construcción de la portada monumental de la Real Fuerza de Ibiza se situarían en un marco evolutivo y de constante perfeccionamiento, del cual llegaría a constituir un punto culminante. Todo ello sin olvidar la filosofía que, de modo creciente, iba

\footnotetext{
${ }^{40}$ Fernando Cobos Guerra - Alicia Cámara Muñoz, «Plan Director de las murallas renacentistas de Eivissa», Félix Julbe Moreno, Eivissa Patrimoni de la Humanitat. Eivissa: Col-legi Oficial d'Arquitectes de les Illes Balears, 2003, p. 74; Joan Ramon Torres, «La ciutat romana...», op. cit., p. 287-288.

${ }^{41}$ Fernando Cobos Guerra - Alicia Cámara Muñoz, De la fortificació d'Yviça. Eivissa: Publicacions de l'Ajuntament d'Eivissa, 2008, p. 138-151.
} 
instalándose en la mentalidad de las clases altas, compuestas por figuras de nobles, militares, ingenieros, artistas, etc., alrededor del poder máximo, encarnado por la soberana figura de Felipe II. ${ }^{42}$

En este contexto, las formas de expresar el poder por parte del Imperio romano y el redescubrimiento de sus antigüedades emblemáticas constituían una verdadera pasión. Ambas cosas fueron de la mano, puesto que, como es bien sabido, las obras de construcción de fortificaciones contemporáneas a la de Ibiza sí fueron acompañadas en otros casos documentados por sus contemporáneos del descubrimiento de elementos monumentales romanos, en el caso de Cartagena y Sagunto, entre otros lugares. Los últimos trabajos en el portal y el cuerpo de guardia tuvieron lugar en 1597 y entre 1590 y 1595 es la fecha que se supone para la instalación de estos elementos.

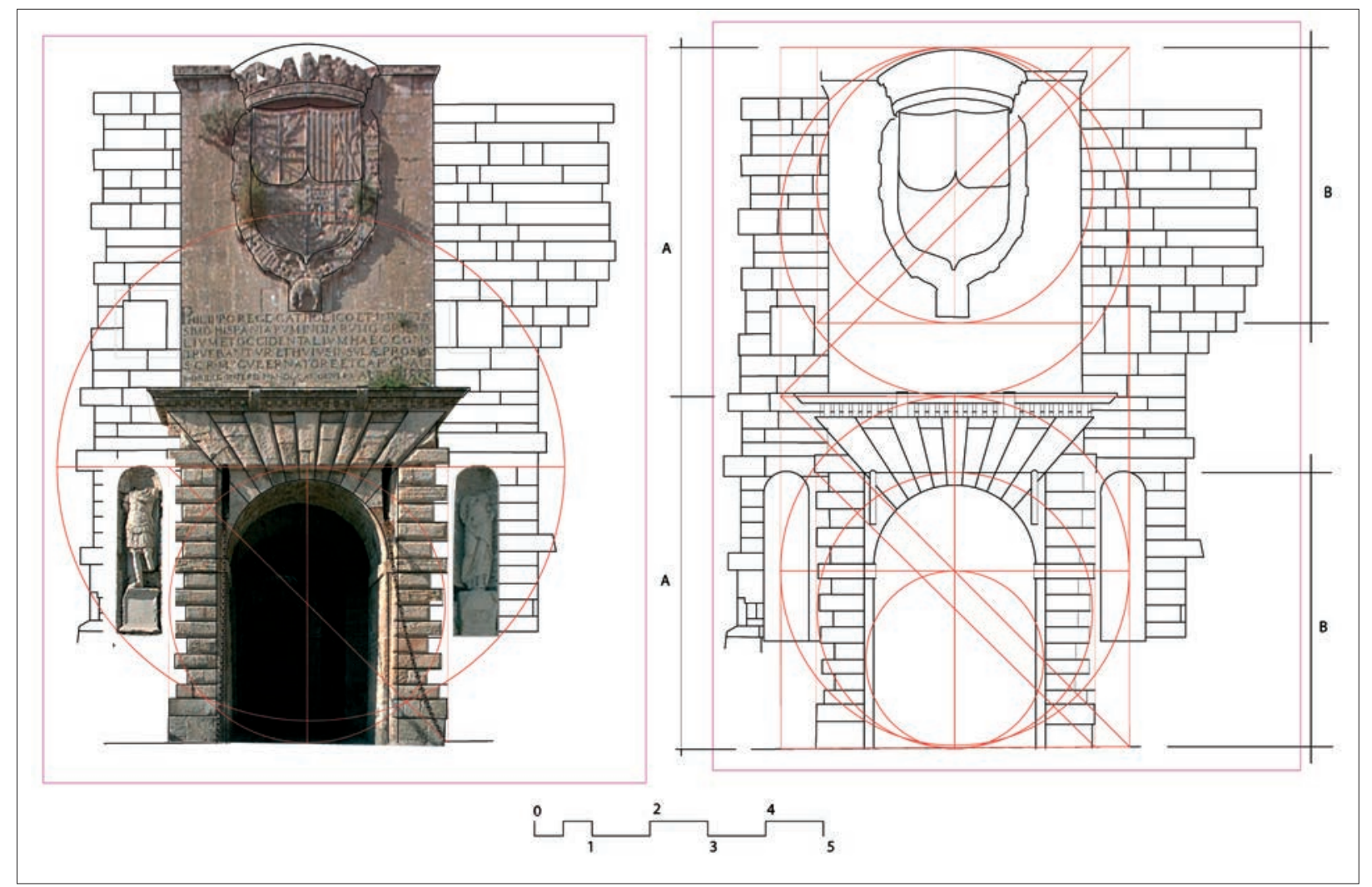

Figura 5. Programa compositivo del Portal de ses Taules (Fuente: F. Cobos y A. Cámara 2008)

\section{El problema desde una óptica transversal}

Cabe advertir, de entrada, que lo que va a argumentarse a continuación concierne las tres estatuas (fig. 3 no 1-3) y la lápida CIL, II, $3361 /$ EREB-3 (fig. $3 \mathrm{n}^{\mathrm{o}}$ ), pero no la votiva CIL, II,
3559 / EREB-1 (fig. 3 no 5 ), cuya piedra caliza, indudablemente local, al margen de la familiaridad de los personajes de la gens Oculacia, reflejada en otros monumentos epigráficos ebusitanos ${ }^{43}$ no ofrece la mínima sospecha en cuanto a su origen insular. Por tanto, su presencia excepcional como

\footnotetext{
${ }^{42}$ Cuestión bien expuesta en Fernando Cobos Guerra Alicia Cámara Muñoz, De la fortificació..., op. cit., p. 145146.
} 29.

${ }^{43}$ Jaime Juan Castelló, «Epigrafía romana...», op. cit., p. 
soporte a la estatua femenina debe ser vista como un complemento puntual al resto de las piezas, que por un motivo u otro (incluido, pero no demostrable, su posible hallazgo a raíz de las obras) estaría a mano en el momento de la construcción; baste ahora recordar su carácter votivo.

El problema debe enmarcarse en los siguientes parámetros:

$1^{\circ}$. En el repertorio de la estatuaria romana que, con seguridad, procede de la isla, las tres piezas por su tamaño y calidad sobresalen muy por encima de un lote de escultura menor, variopinto y de volumen muy reducido (apenas seis fragmentos).

$2^{\circ}$. La consideración de este grupo de monumentos romanos como un verdadero "conjunto", lo que no significa que se tratara, ni desde el punto de vista temporal ni tampoco espacial, de un hallazgo en bloque, que se circunscribe a la última fase de la construcción del acceso monumental a las murallas renacentistas de Ibiza. Con posterioridad a esta fecha (1590-1595) no constan en Ibiza nuevos hallazgos de piezas de esta categoría.

$3^{\circ}$. El hecho de que la figura femenina (fig. 3 no 2), según los estudios específicos realizados al respecto, ya citados, ${ }^{44}$ es en realidad una escultura basada en un prototipo helenístico del tercer cuarto o mediados del siglo II a. C. Su fecha real, aunque probablemente posterior, podría como mínimo anticiparse al inicio del Imperio, mientras que el togado (fig. $\left.3 \mathrm{n}^{\mathrm{o}} 3\right)^{45}$ parece ser de época julio-claudia avanzada, o ya flavia, y el thoracator (fig. $4 \mathrm{n}^{\mathrm{O}} \mathrm{l}$ ), antonina. ${ }^{46}$

4o․ La lápida honorífica CIL, II, $3361 /$ EREB-3 (fig. $3 \mathrm{n}^{\circ} 4$ ), que en la compositiva renacentista del portal de las murallas de Ibiza sustenta la estatua del thoracator, y que, a diferencia del resto de los pedestales mayores, de claro origen

${ }_{44}$ Alberto Balil Illana, «Escultura romana...», op. cit., p. 7, lám. III.

${ }^{45}$ Alberto Balil Illana, «Escultura romana...», op. cit., p. 8, lám. IV-V.

${ }^{46}$ Pilar Acuña Fernández, «Esculturas militares...», op. cit.; Alberto Balil Illana, «Escultura romana...», op. cit., p. 5-6, lám. I-II. ebusitano, es significativamente de mármol y de mucho mejor arte. Se fecha con bastante precisión en el año 106-107 d. C.

Como es bien sabido, contiene una dedicatoria a un personaje de cierta relevancia en la política imperial, Cayo J. Tirón Getúlico, ${ }^{47}$ ya que alcanzó los cargos de cuestor de Roma, tribuno de la plebe y pretor. Fue puesta en relación con un personaje del mismo nombre, que aparece en textos de Suetonio (De grammaticis et rhetoribus) y Plinio el Joven (Ep. 6, 31).$^{48}$ Del mismo modo, el dedicante y amigo del anterior, Lucio Sempronio Seneción, era personaje también relevante, ${ }^{49} \mathrm{con}$ cargos públicos como procurador de la provincia de Judea, entre otros menores, y aparecería igualmente en la mencionada epístola de Plinio e, incluso, en una inscripción de Sidón.

Después se hicieron otras observaciones,${ }^{50}$ que establecieron matices e identificaron a un joven noble, exiliado a una isla y, a decir de Suetonio, avalado por Galba con Cayo J. Tirón Getúlico, y no con L. Calpurnio Pison Frugi Liciniano, como pensó Juan. ${ }^{51}$

Obviamente, no se va a entrar ahora en estas discusiones, porque lo que interesa remarcar ahora, precisamente, es que se trata de personajes reales, desde luego, pero extraños a la ciuitas ebusitana, si se excluye — de hecho, el único argumento

${ }^{47}$ Dicha inscripción aparece en un buen número de estudios, entre los cuales destacan: Raimondo Zucca, Insulae Baliares..., op. cit., p. 265-266; María Luisa Sánchez León, «Ebusus, municipio...», op. cit., p. 58: Enrique García Riaza - María Luisa Sánchez León, Roma y la municipalización..., op. cit., p. 209.

48 Jaime Juan Castelló, «Epigrafía romana...», op. cit., p. 32-39, n을. 3 .

${ }^{49}$ Ibid., p. 104-106, no 39.

${ }^{50}$ Marc Mayer Olivé, "Noves observacions sobre la societat romana de les Balears», María Luisa Sánchez León (coord.), Les Illes Balears a l'Antiguitat: continuitats $i$ ruptures, Mayurqa 29 (2003), p. 150-152: Marc Mayer Olivé, «Les Illes Balears i llur reflex a les fonts literaries i epigrafiques. Revisió d'alguns aspectes», XXIII Jornades d'Estudis Històrics Locals, L'Antiguitat clàssica $i$ la seva pervivència a les illes Balears (2005), p. 44.

${ }^{51}$ Jaime Juan Castelló, «Crassus Frugi su nieto Licinianus en las Islas Baleares», Sylloge Epigraphica Barcinonensis IV (2002), p. 9-19. 
que ha tenido peso hasta la fecha- que esta inscripción perteneció a la Ibiza imperial romana y se considera que el resto de la epigrafía ibicenca no se relaciona jamás con ellos. Además, sus cargos y actividades, a juzgar tanto por la misma inscripción como por el resto de las fuentes literarias relacionables, antes citadas, exceden, llamémosle inhabitualmente, el marco contextual de la isla.

$5^{\circ}$. Lo especialmente sospechoso que resulta el hecho de que se encontraran, o ya existieran por azar, cuatro piezas que, aparte de su calidad intrínseca $-\mathrm{y}$, cabe insistir en ello, no refrendada por otros hallazgos similares - satisficieran al mismo tiempo lo triplemente exigido en cuanto a simbología del escenario renacentista, es decir, lo militar (thoracator por rey o gobernador), lo religioso (estatua femenina por Virgen María) y lo civil (togado por Universidad de Ibiza).

$6^{\circ}$. En contra de lo afirmado por los eruditos de la segunda mitad del siglo XIX y principios del $\mathrm{XX}$ que se ocuparon del tema, no existe ningún dato demostrado en relación con su hallazgo en la propia Ibiza y, mucho menos aún, con que este acaeciera a raíz de las obras de fortificación; el texto de González de Posada - recuérdese, doscientos años posterior a las murallas, pero suficientemente anterior a esta corriente- no refleja sino una situación de absoluta ignorancia, no solo sobre el hallazgo de las piezas romanas, sino tanto o más sobre su significado en la puerta monumental. Por otro lado, y como antes se ha argumentado, no deja de ser un silencio abrumador el hecho de que no se mencionen para nada tan singulares elementos, en un texto literario de P. V. Nicolau, testigo directo de las obras, plasmado en su historia manuscrita, que habla de hallazgos arqueológicos diversos a raíz de la construcción de la tantas veces repetida fortificación.

7ㅇ․ Un hecho imposible de obviar es que este tipo de piezas, en la segunda mitad del siglo XVI, era objeto de una gran movilidad, con la formación incluso de notables colecciones; como no podía ser de otro modo, esta movilidad tuvo un tuvo un carácter bidireccional. En este sentido, es elocuente el caso de la inscripción CIL II, 3663 / EREB-6, ebusitana sin paliativos, puesto que menciona el Municipium Flavium Ebusum, ${ }^{52}$ y exportada lejos de la isla, en esta misma época.

No en vano, Juan Antonio Devi, a su paso por la isla, y a quien se atribuye el hecho, no pudo privarse de inmortalizar su propio cargo (gobernador militar) al más rancio estilo imperial romano, incluidas ligaduras de letras. Lo demuestran dos inscripciones conmemorativas de la construcción, seguramente en dos fases, de la llamada Casa de la Ciudad, en la almudaina de Ibiza, respectivamente de los años 1564 y 1568, donde en ambas se lee: Haec constrvontur Ioane Ant Devi praetore et belli praefecto (fig. 6). ${ }^{53}$ Sin embargo, dicha movilidad se ha valorado solo unidireccionalmente, desde la isla hacia el exterior (como es el caso de la inscripción de los Cornelii) y se ha olvidado que también podía actuar en sentido inverso.

\section{Conclusión}

Aunque es obvio que solo el descubrimiento de nuevos documentos escritos relacionados de un modo más o menos directo con la construcción de las murallas de Ibiza o con los propios monumentos romanos que contienen, sería capaz de zanjar definitivamente un tema como el aquí tratado y, sobre todo, de acallar definitivamente voces críticas que sin duda surgirán contra estas opiniones, el cúmulo de coincidencias y razones encadenadas es lo suficientemente voluminoso para hacer sospechar, en efecto, que todos ellos hecha siempre salvedad de la inscripción a Junopudieron perfectamente haber sido traídos a la isla por encargo expreso de los responsables del diseño del portal renacentista, que actuaron de modo intencional, a plena conciencia, sabiendo perfec-

\footnotetext{
52 Jaime Juan Castelló, «Epigrafía romana...», op. cit.; María Luisa Sánchez León, «Ebusus, municipio...», op. cit., p. 55-64; María Luisa Sánchez León, «Municipium / Res publica en la epigrafía latina de las Islas Baleares», Universidad de Oviedo Memorias de historia antigua XXI-XXII (2000-2001), p. 123-133.

${ }^{53}$ Joan Ramon Torres, «Estudi arqueològic i històric del castell d'Eivissa. I. Estructures i elements arquitectònics», Quaderns d'Arqueologia Pitiüsa 6 (2000), p. 127-130.
} 
tamente de qué piezas se trataba y, no menos, lo que querían expresar con su presencia.

Ya se ha argumentado suficientemente a lo largo de la líneas anteriores que, en la más clara y directa oportunidad de dejar constancia de su hallazgo y/o de su instalación monumental en las murallas, el hecho fue silenciado por completo por P. V. Nicolau, testigo directo de las obras, muy probablemente por un conocimiento directo de que estas piezas eran ajenas a la antigüedad ebusitana.

Por otro lado, González de Posada, el primer erudito que poco antes de acabar el siglo XVIII, justo doscientos años después de su colocación en las murallas, trató de estas piezas, no pudo abstraerse de una realidad: ya nadie recordaba, ni el significado - cuyo conocimiento original, tal vez premeditadamente, se redujo a un círculo intelectual muy restringido- en el portal monumental ni su historia anterior. Por ello, dio cuenta de una creencia que, andados los años, se habría formado y que de algún modo debía de seguir vigente en su época, que representaban a los conquistadores catalanes del siglo XIII, opinión que rechazó al calificar correctamente las piezas de romanas.

En todo caso y en contra de lo que han creído algunos investigadores modernos, ${ }^{54} \mathrm{el}$ primer canónigo magistral en ningún momento dijo que fueran halladas durante la construcción de la fortaleza, sino que se hallaban «en otra parte hasta el reinado de Felipe II». Lástima que no precisara, sin duda porque lo ignoraba, en qué parte concretamente.

Así pues, tuvieron que transcurrir más de doscientos sesenta años desde los hechos, para que, sin ninguna prueba fehaciente, haciendo gala de una imaginación desbordante, empezara a divulgarse la suposición de su hallazgo casual por causa de dichas obras de fortificación, como se ha visto, inaugurada por Aranaz en 1859 y consagrada «definitivamente» por Román Calvet en 1906.

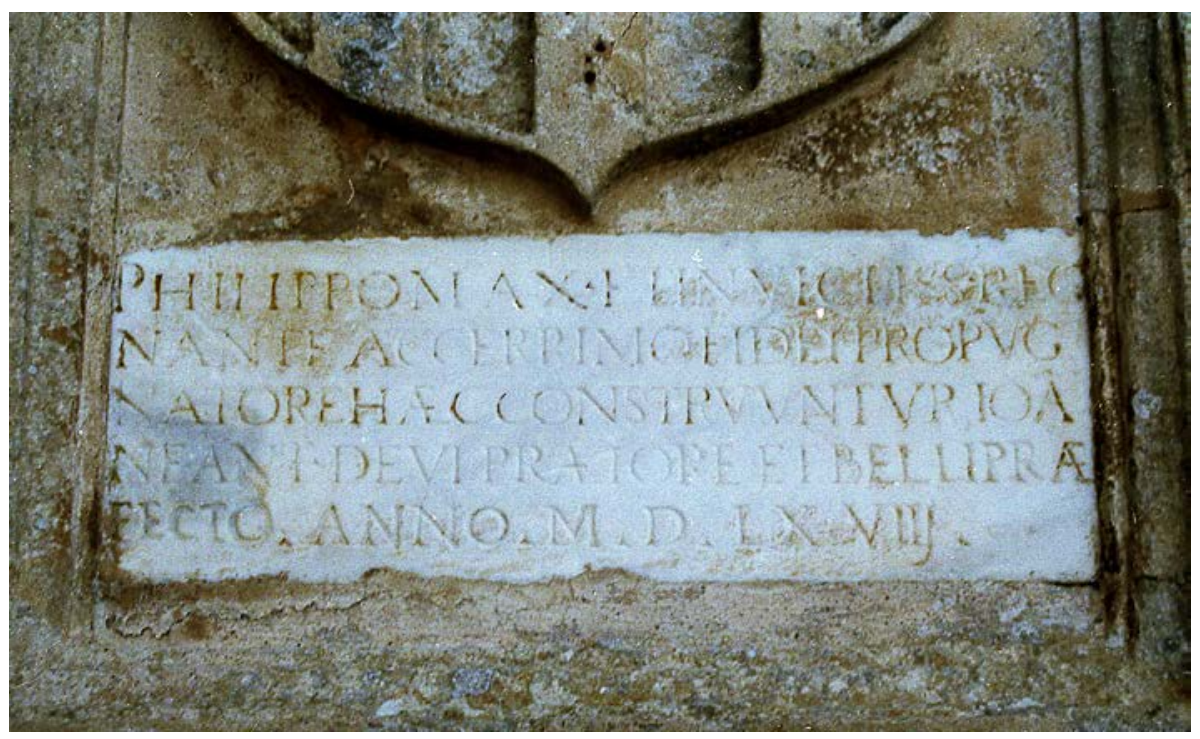

Figura 6. Inscripción de Juan Antonio Devi, de 1568, en la puerta de la planta superior de la Casa de la Ciudad, Almudaina de Ibiza (Fuente: foto del autor).

${ }^{54}$ P. ej., Jaime Juan Castelló, «Epigrafía romana...», op. cit., p. 27. 
Es evidente que la presencia de estas piezas en las murallas ibicencas de Felipe II encuentra una explicación convincente solo en el marco conceptual y simbólico del momento en que fueron construidas y en la coyuntura de recuperación y, no se olvide, de coleccionismo de obras de arte clásicas, que llegó a instaurarse entre las clases altas. Su significado, pues, no solo era simplemente ornamental, como tantos han creído, sino ante todo ideológico y político. No en vano, tras la exaltación del Imperio romano, se hallaba la justificación del propio Imperio, que Felipe II heredó de su padre, Carlos V; los arqueólogos e intelectuales franceses durante la colonización del norte de África, en la segunda mitad del siglo XIX y buena parte del XX, aun actuando con idéntica filosofía, no inventaron nada nuevo.

Únicamente, un «mercado» amplio y, por fuerza, extrainsular podía abastecer de piezas con la simbología requerida en cada una de las estatuas, las del portal principal, el guerrero y la diosa, sobre pedestales que, como corresponde a su rango y posición en la entrada monumental, realzan aún más su majestuosidad. Como es lógico, y a pesar de que en aquellas épocas la capacidad del pueblo llano para leer inscripciones de este tipo era poco elevada, por no decir literalmente nula, bien cuidaron el detalle de que dichos pedestales no llevaran dedicatorias funerarias que, dicho sea de paso, son las más corrientes en la Ibiza romana.

$\mathrm{Y}$ otro hecho, no intrascendente aquí, es que la representación del togado, alegoría del poder civil, menos importante, y premeditadamente situada en la trastienda del acceso principal, no fue dotada de ninguna base.

En síntesis, hoy por hoy, el origen ebusitano de las tres estatuas romanas y de uno de los dos pedestales de las murallas renacentistas de Ibiza no solo es indemostrable, sino que, por las razones antes expuestas, parece improbable de todo punto.

¿Cuál es, pues, la merma que provocaría el nuevo planteamiento en la Ebusus romana? En el fondo, tal vez no mucha. La primera, desde luego, que la afición por las grandes estatuas no sería muy significativa en Ibiza durante el Alto Imperio, sin que ello deba ser llevado, al menos por ahora, al terreno de una resistencia a la romanización; otros aspectos, que no vienen ahora al caso, sugieren más bien lo contrario. Dicho esto, nada impide que Ebusus tuviera su foro, en rigor no localizado por ahora, aunque presumible en el llano de La Marina ${ }^{55}$ e incluso que la repetidamente mencionada lápida dedicada a Juno por personajes claramente ibicencos y excepción a lo dicho para el resto de los monumentos romanos en el portal renacentista estuviera originalmente instalada en él, junto con otras inscripciones honoríficas, algunas conocidas por viejos documentos, pero desaparecidas desde hace muchos años. ${ }^{56}$

En cambio, sí cabría descartar el conjunto de deducciones sociopolíticas e incluso económicas - coherentes desde otra perspectiva - en relación con el vínculo con Ibiza de Cayo J. Tirón Getúlico y Lucio Sempronio Seneción, puesto que la única base para ello, hasta ahora, ha sido precisamente, y valga la redundancia, el supuesto lugar de hallazgo del pedestal.

Como colofón, una observación de perfil más bien patrimonial, el traslado en el inicio de los años 80 de los originales al Museo de Ibiza fue una decisión ${ }^{57}$ que, aun suponiendo que estos monumentos eran legado de la Ebusus imperial, como entonces era el caso, jamás hubieran refrendado ni los propios fundadores del museo. ${ }^{58}$ Por encima de cualquier otra consideración, se trata

${ }_{55}$ Joan Ramon Torres, «La ciutat romana...», op. cit., p. 296-297

${ }^{56}$ Jaime Juan Castelló, «Epigrafía romana...», op. cit., p. 85 y ss.

${ }^{57} \mathrm{He}$ aquí los argumentos: «los originales fueron trasladados al Museo, donde han sido sometidos a los tratamientos convenientes de restauración y donde quedaron definitivamente depositados, con el fin de garantizar su buena conservación» (vid. Benjamín Costa Ribas - Jorge H. Fernández Gómez, Ibiza y Formentera..., op. cit., p. 70). Ciertamente, las piezas romanas necesitaban una limpieza profunda, igual que todo el conjunto amurallado, tras no menos de 385 años de estar a la intemperie, eso sí, atenuada por el hecho de dar la espalda a la trayectoria solar, a pesar de lo cual su estado de conservación era más que aceptable.

${ }^{58}$ Vid. a contrario sensu lo mencionado antes, que Pérez-Cabrero pretendía colocar «en su sitio correspondiente» - y no a la inversa- una cabeza romana, entonces en el Museo, que supuso pertenecía a la estatua femenina del Portal de ses Taules. 
de monumentos romanos que, a través de su importación expresa a Ibiza, pero no en época imperial, sino renacentista, desde un lugar o lugares por desgracia desconocidos, formaron ya en origen un grupo indisoluble en el programa de un monumento mucho mayor, la fortificación renacentista de Ibiza, hoy en sí misma un verdadero museo.

Ahora, y desde la perspectiva aquí defendida, dicho traslado parece no solo como aún más injus- tificado sino también absurdo, por lo que tiene el hecho de exhibir como tales semejantes obras de ignorado origen en un museo dedicado exclusivamente a elementos arqueológicos insulares. Los monumentos romanos en la Puerta del Mar fueron, pues, cambiados por reproducciones de una calidad y ejecución, eso sí, impecable, de modo que poco después ya se confundían con los originales que tuvieron en su día; tal vez sería tiempo de replantearse dicha sustitución. ${ }^{59}$

${ }^{59} \mathrm{Y}$, en el caso de considerarse necesario su mantenimiento a cubierto, los espacios musealizados y cerrados, que modernamente se han ido creando en los diversos baluartes de la fortificación, que recrean ambientes del siglo XVI, serían un locus statuae mucho más lógico. 